\title{
Sensory Threshold of Off-Flavors Caused by Proteolysis and Lipolysis in Milk ${ }^{1}$
}

\author{
M. V. Santos, ${ }^{\star}$ Y. Ma,† Z. Caplan, $†$ and D. M. Barbano† \\ *Departamento de Nutrição e Produção Animal, \\ Faculdade de Medicina Veterinária e Zootecnia, \\ Universidade de São Paulo, Pirassununga, SP, Brazil \\ †Northeast Dairy Foods Research Center, \\ Department of Food Science, \\ Cornell University, Ithaca, NY 14853
}

\section{ABSTRACT}

The objective of this study was to determine the sensory threshold of off-flavor caused by lipolysis in $2 \%$ fat milk and to establish the relationship between increased proteolytic activity in milk and the detection of bitter off-flavor. Homogenized raw milk was held at room temperature for 100 min to allow the native milk lipase to release free fatty acids from the triglycerides. Low and high lipolysis pasteurized milk containing $2 \%$ fat were blended together in varying amounts to create a series of six milks with increasing free fatty acid (FFA) concentration for sensory evaluation. Sensory threshold for lipolysis in $2 \%$ fat milk was determined by ascending forced-choice procedure, with a series of triangle tests in four sessions with 25 panelists in each session. The group best estimated threshold was the geometric mean of the individual thresholds within each of four panel sessions. The geometric mean best estimated detection thresholds for off-flavors caused by lipolysis in $2 \%$ fat milk carried out by native milk lipases were $0.320,0.322,0.351$, and 0.316 meq of FFA/ $\mathrm{kg}$ milk for panels 1 to 4 , respectively. One third of the panelists detected an off-flavor at or below 0.250 meq of FFA/kg milk. To establish the relationship between proteolysis and detection of off-flavor in pasteurized skim milk, $2800 \mathrm{ppm}$ of $\mathrm{CO}_{2}$ were added to pasteurized skim milk, and it was stored for $27 \mathrm{~d}$ at $6^{\circ} \mathrm{C}$. Another portion of the same milk was frozen on $\mathrm{d} 1$ at $-40^{\circ} \mathrm{C}$ for use as a low proteolysis portion of the same milk. Decrease in casein as a percentage of true protein $(\mathrm{CN} /$ $\mathrm{TP}$ ) was used as an index of proteolysis. After $27 \mathrm{~d}$ at $6^{\circ} \mathrm{C}$ the milk had a decrease in CN/TP of $4.76 \%$ and a

Received May 27, 2002.

Accepted September 3, 2002.

Corresponding author:D. M. Barbano; e-mail:dmb37@cornell.edu.

${ }^{1}$ Use of names, names of ingredients, and identification of specific models of equipment is for scientific clarity and does not constitute any endorsement of product by authors, Cornell University, Universidade de São Paulo, or the Northeast Dairy Foods Research Center. standard plate count of $430 \mathrm{cfu} / \mathrm{ml}$. The novel approach of storing milk at $6^{\circ} \mathrm{C}$ for $27 \mathrm{~d}$ with added $\mathrm{CO}_{2}$ blocked microbial growth but allowed proteolytic degradation by milk enzymes to proceed. Before sensory analysis, $\mathrm{CO}_{2}$ was removed by vacuum from the high proteolysis milk and the low proteolysis milk was given the same heat and vacuum. Two triangle tests were performed to determine whether panelists could detect off-flavors caused by proteolysis in milk. The threshold detection of off-flavor in skim milk produced by the action of native milk proteases was less than a decrease of CN/TP of $4.76 \%$, but this value is probably near the threshold. (Key words: proteolysis, lipolysis, sensory threshold, milk off-flavor)

Abbreviation key: BET = best estimated threshold, $\mathbf{C C}=$ coliform count, $\mathbf{C N / T P}=$ casein as a percentage of true protein, SPC $=$ standard plate count.

\section{INTRODUCTION}

Consumer acceptance of fluid milk is strongly determined by its sensory characteristics, such as flavor as well as by its nutritional value. The development of offflavors in milk as a result of lipolysis and proteolysis can reduce shelf life and quality of pasteurized fluid milk (Ma et al., 2000).

The hydrolytic release of free fatty acids from triglycerides causes a flavor defect in fluid milk described as 'rancid' (Shipe et al., 1978). This event, known as lipolysis, occurs as milk lipase catalyzes the release of free fatty acids from triglycerides. Bovine milk contains a native lipase (Castberg, 1992) that is characterized as a lipoprotein lipase (EC 3.1.1.34). Other lipolytic enzymes that may play a role in lipolysis in milk are: lipase from somatic cell origin, bacterial lipases and other miscellaneous esterases (Azzara and Dimick, 1985). In fresh, high quality milk, lipolysis is caused mainly by the activity of milk lipoprotein lipase (Olivecroma, 1992). In cow's milk, the majority of lipase is associated with the casein micelles in the skim milk 
fraction. Ma et al. (2000) reported that high SCC pasteurized milk stored at $5^{\circ} \mathrm{C}$ developed rancid off-flavor between 14 and $21 \mathrm{~d}$ after processing, whereas low SCC milk did not. They hypothesized that somatic cells may have contributed heat stable lipases that survived pasteurization.

Proteolysis of milk during storage can result in the accumulation of small peptides that lead to the development of bitterness (Ma et al., 2000) and astringency (Harwalkar et al., 1993). Proteolytic activity in raw milk with low bacteria count is due mainly to the endogenous milk protease plasmin (EC 3.4.21.7). Plasmin activity in milk increases with increasing milk SCC. The major substrate for proteolysis in milk is casein. Plasmin is one major protease in milk acting mainly on $\alpha_{\mathrm{s}^{-}}, \alpha_{\mathrm{s} 2^{-}}$, and $\beta$-casein (Verdi et al., 1987). During mastitis, not only the concentrations of plasmin and plasminogen are increased, but the rate of plasminogen activation is also increased (Politis et al., 1988). In normal milk, plasmin is the enzyme responsible for most of the proteolytic activity (de Rham and Andrews, 1982). During mastitis, when milk SCC is elevated, the proteolytic contribution from phagocytic leukocytes (polymorphonucleocytes and macrophages) is greatly increased (de Rham and Andrews, 1982; Verdi and Barbano, 1988). These cells contain active proteases, especially when activated by the immune response (Verdi and Barbano, 1991). Contribution of nonplasmin proteolytic activity from somatic cells is usually only significant when SCC is maintained high, at a level of 1 million cells/ml or higher (Saeman et al., 1988; Verdi and Barbano, 1988). In the present study, milk with elevated SCC was selected to provide milk that would develop off-flavors due to the action of native milk proteases after pasteurization. When postpasteurization contamination is eliminated and bacteria counts are kept low during refrigerated storage of fluid milk, the activity of the native milk lipases and proteases will become the factor that limits shelf-life of fluid milk.

According to Lawless and Heymann (1998), ascending forced-choice procedures are widely used techniques for threshold measurements for taste and smell. The sensory threshold concept is useful for the dairy industry in determining the minimum concentration of an off-flavor compound that would be detected in pasteurized milk by the consumers. Classically, in sensory research, a flavor threshold is estimated as the geometric mean of all panelist thresholds.

The objective of this study was to determine the sensory threshold of off-flavor caused by lipolysis in $2 \%$ fat milk using the ascending forced-choice method and to establish the relationship between increased proteolytic activity in milk and the detection of off-flavor.

\section{MATERIALS AND METHODS}

\section{Experiment 1. Sensory Threshold of Off-Flavors Caused by Lipolysis}

Controlled production of lipolytic off-flavor. Babcock tests were performed on raw cream (AOAC, 2000; method number 33.3.18; 995.18) and raw skim milk (Marshall, 1993; method number 15.8B) to control the standardization process to produce $2 \%$ fat milk. For the experimental control (low lipolytic off-flavor), raw $2 \%$ fat milk was heated to $65.5^{\circ} \mathrm{C}$ in a steam-jacketed kettle and then homogenized (first stage, $13.8 \mathrm{MPa}$; second stage, 3.5 $\mathrm{MPa}$ ) in a two-stage homogenizer (model 75E, Gaulin, Everett, MA). The milk was then immediately pasteurized in a small-scale shell and tube pasteurizer at $76^{\circ} \mathrm{C}$ for $30 \mathrm{~s}$. This temperature and holding time in this system produces a level of heat denaturation of whey protein similar to that observed in commercial pasteurized fluid milk processed and marketed in northeast United States (Ma et al., 2000). The milk was cooled to $4^{\circ} \mathrm{C}$ and collected in 1.8-L plastic containers. The containers were then stored in an ice bath and covered in black plastic bags to prevent light oxidation.

Milk with native milk lipase-induced off-flavor was produced by heating raw $2 \%$ fat milk to $32^{\circ} \mathrm{C}$ in a steamjacketed kettle and then homogenizing (first stage, 13.8 $\mathrm{MPa}$; second stage, $3.5 \mathrm{MPa}$ ) that milk. The homogenized milk was held at room temperature for $100 \mathrm{~min}$ to allow the native milk lipase to release free fatty acids from the triglycerides. The milk with the lipase-induced off-flavor was then heated to $65.5^{\circ} \mathrm{C}$ and homogenized again achieve the same particle size of milk fat globules as the low lipolytic off-flavor control portion. The milk was then immediately pasteurized (i.e., to stop lipolysis) cooled, collected, and stored under the same conditions as the control. The above processing procedures were performed twice in two different weeks with different batches of milk.

Milk quality evaluation-chemical analysis. The extent of lipolysis was measured using the copper soap method (Shipe et al., 1980), as modified by Ma et al. (2003). Alkaline phosphatase tests were run on each batch of control and experimental milk to determine whether the batches were fully pasteurized using the Charm PasLite method (Charm Science Inc., Malden, MA). Particle size analyses were run on each batch of milk according to Smith et al. (1995), using a laser lightscattering particle size analyzer (MasterSizer model E; Malvern, Worcestershire, United Kingdom) to determine whether the experimental portions were homogenized similarly, thus ensuring that a difference in mouth feel would not affect the sensory evaluation. 
Preparation of samples. For replicate one, the FFA contents of the low and high lipolysis milks were 0.11 and $0.99 \mathrm{meq} \mathrm{FFA} / \mathrm{kg}$ of milk, respectively. For replicate two, the FFA contents of the low and high lipolysis milks containing $2 \%$ fat were 0.12 and 0.87 meq of FFA/ $\mathrm{kg}$ of milk, respectively. The low and high FFA portions of milk were blended together in varying amounts to create a series of milks with increasing FFA concentrations. A series of six samples with increasing FFA content were prepared so that: 1) the difference in FFA content between adjacent increments doubled as the FFA concentration increased and 2) the expected detection threshold (based on preliminary work) would occur in the middle of the series of six samples. The six different experimental samples were compared to the low FFA control milk. The samples were poured into plastic cups with lids and stored at $6^{\circ} \mathrm{C}$ in opaque containers to protect them from light until they were served to the panel.

Milk quality evaluation-sensory analysis. Ascending forced-choice procedures were used to measure the detection threshold (Lawless and Heymann, 1998). The use of human subjects in this study was reviewed and approved by the Cornell University Committee on Human Subjects. Stimulus intensity (i.e., FFA concentration) was increased in a series of triangle tests, in an ascending fashion, to find points where each individual panelist's responses changed from not correctly identifying the odd sample to correctly identifying the odd sample. The samples were provided to each panelist as a series of six blind coded sets of three samples per set. The first set was two portions of low FFA milk and the next lowest concentration of high FFA milk. The panelist had to make a choice of the odd sample before they would receive the second set, and so on for six sets. Twenty-five untrained panelists participated in each sensory panel. Two separate groups of 25 untrained panelists were used for each replicate, for a total of four taste panel sessions. Paper ballots with symbols (e.g., $\propto, \bullet$, \#, etc.) for each milk sample were used.

The individual and group best estimated threshold (BET) during each sensory session was calculated as described by Meilgaard et al. (1991). The individual BET was calculated as the geometric mean of the highest concentration missed and the next concentration (Meilgaard et al., 1991). For those panelists who were correct at the lowest FFA concentration, their individual BET were estimated as the geometric mean of the lowest FFA concentration tested in the study, and the hypothetical next lower FFA concentration that would have been given had the series been extended (i.e., 0.162 meq of FFA $/ \mathrm{kg}$ of milk for processing wk 1 and 0.158 meq of FFA/kg of milk for processing wk 2; Lawless and Heymann, 1998). Similarly, for those panelists who failed to correctly identify the odd milk sample at the highest FFA concentration, their individual BET were estimated as the geometric mean of the highest FFA concentration tested in the study and the hypothetical next higher FFA concentration that would have been given had the series been extended (i.e., 1.750 meq of $\mathrm{FFA} / \mathrm{kg}$ of milk for processing wk 1 and 1.566 meq of FFA/kg of milk for processing wk 2) (Lawless and Heymann, 1998). For each of the four tasting sessions, the group BET was the geometric mean of the individual BET (Meilgaard et al., 1991; Lawless and Heymann, 1998).

\section{Experiment 2-Sensory Threshold of Off-Flavors Caused by Proteolysis}

Milk processing. Milk samples collected from 50 Holstein cows at the Cornell Teaching and Research Center were screened for fat and protein content (AOAC, 2000; method number 33.2.31; 972.16) and SCC (AOAC, 2000; method number 17.13.01; 978.26) $3 \mathrm{~d}$ before milk collection. Six cows that produced milk with high SCC ( $>800,000$ but $<1,000,000$ cells $/ \mathrm{ml})$ were selected.

On the day of milk collection, all the milk from one milking was collected separately from each of the cows producing high SCC milk. Milk yield was recorded. Raw milk from individual cows was immediately transported to Cornell Food Science Department Pilot Plant and rapidly cooled in ice to $4^{\circ} \mathrm{C}$. Samples of the milk from each cow were taken and preserved with Bronopol tablets (Preservative System Limited, San Francisco, CA) and tested for SCC (AOAC, 2000; method number 17.13.01, 978.26). Based on the SCC results on the collection day, raw unpreserved milks from individual cows were commingled into one batch with high SCC (six cows, average 775,000 cells $/ \mathrm{ml}$ ).

The commingled high SCC raw milk was heated and separated at $49^{\circ} \mathrm{C}$ into skim and cream using a cream separator (model 100; DeLaval, Poughkeepsie, NY). Fat content of skim milk (Marshall, 1993; method number 15.8B) was determined by the Babcock method. Skim milk was immediately pasteurized (HTST, $76^{\circ} \mathrm{C} / 30 \mathrm{~s}$ ) in a shell and tube pasteurizer and cooled to $4^{\circ} \mathrm{C}$. Pasteurization was confirmed by the phosphatase test (Charm PasLite method; Charm Science Inc., Malden, MA). Based on previous work (Ma et al., 2000), we expected that the native milk protease activity would be high in this milk, due to the high SCC, and that this protease activity would survive pasteurization (Richardson, 1983, Ma et al., 2000).

To serve as a low proteolysis control for detection of off-flavors caused by proteolysis, a portion of the fresh pasteurized skim milk was placed in plastic containers 
and immediately frozen at $-40^{\circ} \mathrm{C}$ until needed for the sensory tests. Another portion of the pasteurized skim milk was injected with $\mathrm{CO}_{2}$ in a continuous flow shell and tube system at 2 to $3^{\circ} \mathrm{C}$ and then held at $6^{\circ} \mathrm{C}$ for $27 \mathrm{~d}$ to create a milk with a high degree of proteolysis. A target level of $2800 \mathrm{ppm}$ of $\mathrm{CO}_{2}$ was added to milk to inhibit microbial growth (Hotchkiss et al., 1999) and thus avoid confounding effects of microbial derived offflavors not associated with proteolysis that otherwise could develop during storage of the milk at $6^{\circ} \mathrm{C}$ for 27 d. Skim milk was used instead of $2 \%$ milk to avoid any confounding effects of fat degradation during milk storage. The $\mathrm{CO}_{2}$-treated skim milk was stored in dark plastic sealed containers for $27 \mathrm{~d}$ at $6^{\circ} \mathrm{C}$ to allow degradation of milk proteins by native milk proteases and development of associated off-flavor. After $24 \mathrm{~d}$ of storage, the frozen control skim milk was removed from a $-40^{\circ} \mathrm{C}$ freezer and thawed during $48 \mathrm{~h}$ at $6^{\circ} \mathrm{C}$. On $\mathrm{d} 26$, both milks were carried through the process to remove the $\mathrm{CO}_{2}$. This was done by heating $1000-\mathrm{ml}$ batches of milk to $50^{\circ} \mathrm{C}$ for $25 \mathrm{~min}$ using a rotary evaporator with heated water bath (Rotavapor model RE 111, Büchi Labortechnik AG, Switzerland), and removing the $\mathrm{CO}_{2}$ using a vacuum at $635 \mathrm{~mm}$ of $\mathrm{Hg}$. After the $\mathrm{CO}_{2}$ removal, both milks were cooled to $6^{\circ} \mathrm{C}$ and prepared for sensory analysis.

Preparation of samples and sensory analysis The decrease in casein as a percentage of true protein (CN/TP) of low and high proteolysis skim milk was 0 and $4.76 \%$, respectively. It was estimated from previous research (Ma et al., 2000) that the sensory threshold for detection of off flavor due to proteolysis would be about a $4 \%$ decrease in CN/TP. The two low and high proteolysis milks were poured into plastic cups with lids in advance of the panels. The high and low proteolysis milks were stored for several hours at $6^{\circ} \mathrm{C}$ and kept closed in coolers to protect them from light until served to the panelists.

Triangle tests were used to determine whether panelists could detect off-flavor caused by proteolysis in milk (Lawless and Heymann, 1998). The samples were provided to each panelist as two sets of three samples per set. The first set had two samples with low proteolysis and one with high proteolysis milk. The second set had two samples with high proteolysis and one with low proteolysis milk. The order of sample presentation was randomized. The panelist had to make a choice of the odd sample for the first set before they would receive the second set. Twenty-five panelists participated. The numbers of panelists that correctly selected the odd sample for each of the two sets were recorded.
Table 1. The FFA concentrations (meq/kg of milk) of milks containing $2 \%$ fat for the ascending series of six samples with lipolyzed off-flavor and the low FFA control for replicate 1 and 2.

\begin{tabular}{llllllll}
\hline & \multicolumn{7}{c}{ Samples } \\
\cline { 2 - 8 } Replicate & Control & 1 & 2 & 3 & 4 & 5 & 6 \\
\hline 1 & 0.11 & 0.175 & 0.200 & 0.250 & 0.350 & 0.550 & 0.950 \\
2 & 0.12 & 0.180 & 0.202 & 0.246 & 0.334 & 0.510 & 0.862 \\
\hline
\end{tabular}

\section{RESULTS AND DISCUSSION}

\section{Standardization and Pasteurization of Milks}

The fat content of both control and high FFA milks were $2 \pm 0.1 \%$ fat. The fat content of the skim milk in this study was $0.05 \%$. The phosphatase analysis confirmed that all milks were fully pasteurized. Particle size analysis revealed that the volume mean diameter [D $(4,3)]$ was similar for the low FFA milk $(0.90 \mu \mathrm{m})$ and high FFA milk $(0.82 \mu \mathrm{m})$. In a previous survey (carried out in our laboratory) of milk fat globule size distribution typically observed in commercial fluid milks in the Northeast region, 122 homogenized milks from 40 plants were obtained. Fat globule volume mean diameter of these commercial homogenized milks averaged $0.89 \mu \mathrm{m}$ with a standard deviation of $0.14 \mu \mathrm{m}$. Thus, the milks in the current study were properly homogenized and had fat globule size distribution similar to commercial fluid milks.

\section{Sensory Detection Threshold of Off-Flavors Caused by Lipolysis in Milk}

The FFA concentrations in the ascending series of milk for replicate one and for replicate two are shown in Table 1. The low FFA control replicate contained 0.11 meq of FFA $/ \mathrm{kg}$ of milk and 0.12 meq of FFA/ kg of milk for replicate two. The samples had a large enough range of FFA so that 83 out of 100 panelist had two adjacent increments where they correctly identified odd samples. The group BET were 0.320, 0.322, 0.351, and 0.316 meq of FFA $/ \mathrm{kg}$ of milk for panel sessions one through four, respectively (Figure 1).

There was a wide range of thresholds among panelists. The cumulative frequency distribution of the individual BET is shown in Figure 2. Approximately $63 \%$ of the panelists had detection thresholds at, or below, 0.35 meq of $\mathrm{FFA} / \mathrm{kg}$ of milk containing $2 \%$ fat. In the range of FFA concentrations from 0.17 to 0.20 meq FFA/ $\mathrm{kg}$ of milk containing $2 \%$ fat, $13 \%$ of the panelists could detect the off-flavor. When the FFA concentration reached 0.25 meq of $\mathrm{FFA} / \mathrm{kg}$ of milk containing $2 \%$ fat, $34 \%$ of the panelists could detect the off-flavor. This 

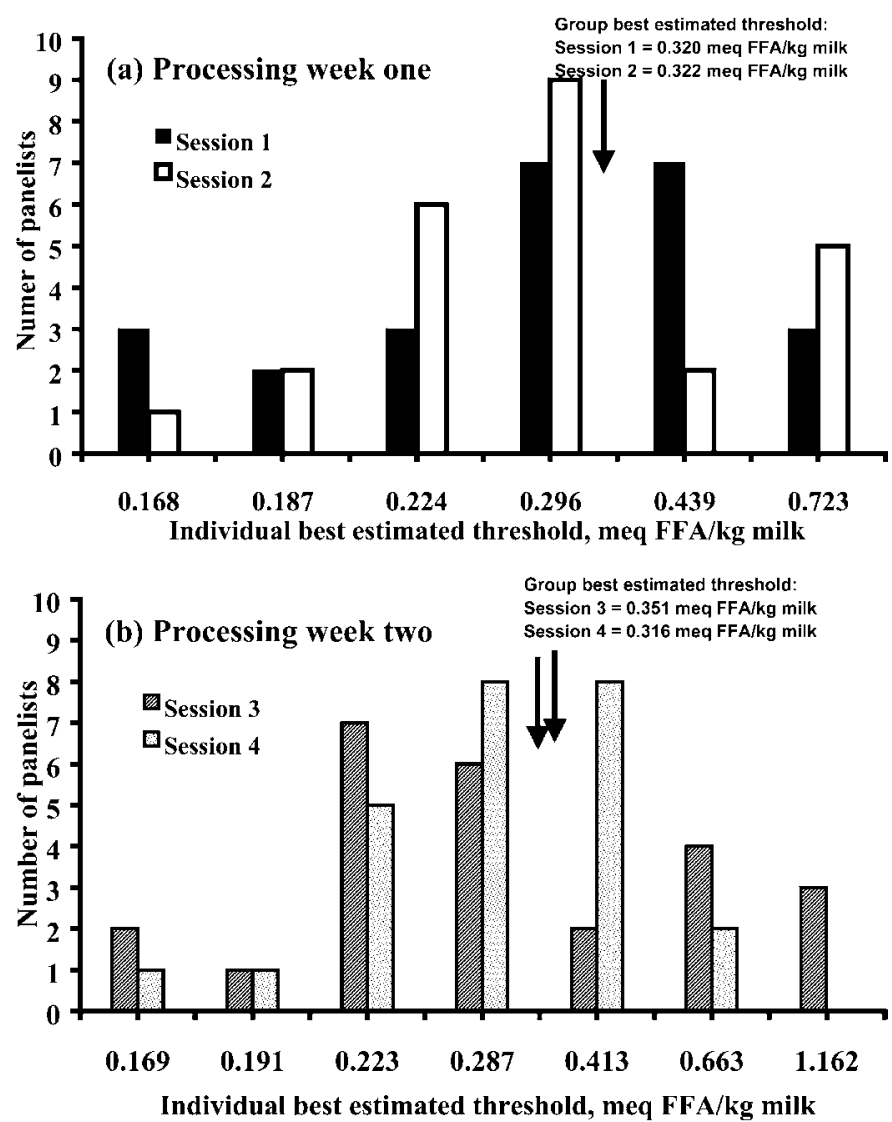

Figure 1. Histogram of individual best estimated thresholds (BET) determined in panel sessions one through four during processing wk 1 (a) and 2 (b). Group BET was the geometric mean of the individual BET's for each session.

creates a dilemma for milk marketing and quality assurance for fluid milk processors. With a wide range of individual consumer sensory thresholds for rancid offflavor, what is an acceptable percentage of consumers who can detect a rancid off-flavor in milk containing $2 \%$ fat? This perception needs to be considered along with the numbers of days of shelf life when setting product quality goals. For example, a processor may want to set a milk quality goal that the FFA content of $2 \%$ fat milk should be low enough so that no more than $34 \%$ of customers will detect a rancid off-flavor at $21 \mathrm{~d}$ of shelf life. Then, in this example the processor would need to determine what raw milk quality is needed and what control of post pasteurization microbial contamination would be required to achieve a FFA concentration of $<0.25$ meq of FFA/kg of milk with $2 \%$ fat at $21 \mathrm{~d}$ of storage. The storage temperature assumption is a critical part of this evaluation. The same general thinking could be applied to any target of storage life for fluid milk.

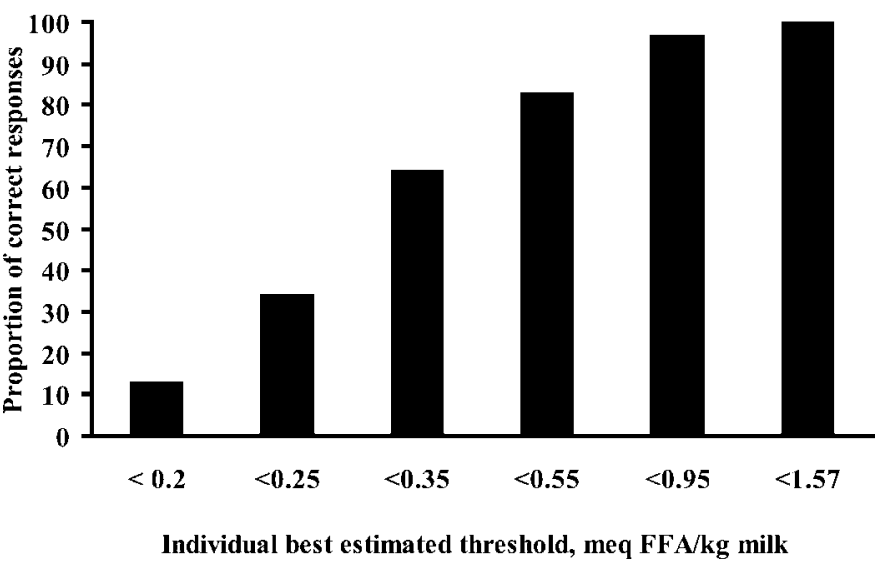

Figure 2. Cumulative frequency distribution of individual best estimated detection threshold for lipolytic off-flavor in $2 \%$ fat milk. Data from the four panel sessions were combined.

\section{Sensory Detection of Off-Flavors Caused by Proteolysis in Milk}

The composition of both low and high proteolysis milk before and after the storage period is presented in Table 2. During the storage period, the high proteolysis milk had more proteolysis than the control. The decrease in $\mathrm{CN} / \mathrm{TP}$ was $4.76 \%$ in $27 \mathrm{~d}$ at $6^{\circ} \mathrm{C}$. Standard plate count (SPC) and coliform count (CC) of pasteurized low and high proteolysis skim milk before storage were 8 and $<1 \mathrm{cfu} / \mathrm{ml}$ and 8 and $<1 \mathrm{cfu} / \mathrm{ml}$, respectively, and after storage period were 7 and $<1 \mathrm{cfu} / \mathrm{ml}$, and 430 and $<1$ $\mathrm{cfu} / \mathrm{ml}$, respectively (Table 2 ). The novel approach of storing milk at $6^{\circ} \mathrm{C}$ for $27 \mathrm{~d}$ with $\mathrm{CO}_{2}$ blocked microbial growth but allowed the degradation of milk proteins by native milk enzymes. We would have liked to have achieved a higher level of proteolysis. Before sensory panel testing, the study directors had a few expert panelists taste, in a triangle test, low and high proteolysis milks. While they could detect a difference, it was agreed that the difference was small. It was decided that a dilution series of the high proteolysis milk would not be useful because the threshold values would not be in the middle of range of the ascending dilution series. Therefore, a triangle test was used to determine whether untrained panelists could detect a difference between the low and high proteolysis milk samples.

In the first set of the sensory test, panelists were asked to choose the odd sample in a triangle test with two control low proteolysis milk samples (decrease in $\mathrm{CN} / \mathrm{TP}=0 \%$ ) and one high proteolysis milk sample (decrease in CN/TP $=4.76 \%)$, and 13 out of $25(52 \%)$ correctly identified the odd sample, which is significant at $P<0.05$ (Lawless and Heymann, 1998). When the same panelists were asked to choose the odd sample in a triangle test with two high proteolysis milk samples 
Table 2. Composition and bacteria counts of low and high proteolysis skim milk before and after storage for $27 \mathrm{~d}$.

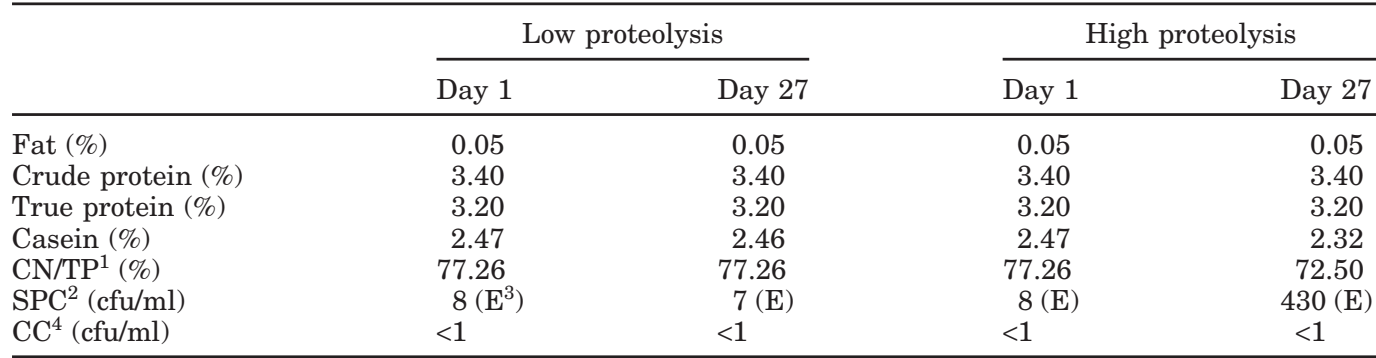

${ }^{1} \mathrm{CN} / \mathrm{TP}=$ Casein as a percentage of true protein.

${ }^{2} \mathrm{SPC}=$ Standard plate count.

${ }^{3} \mathrm{E}=$ Estimated.

${ }^{4} \mathrm{CC}=$ Coliform count.

(decrease in $\mathrm{CN} / \mathrm{TP}=4.76 \%$ ) and one low proteolysis milk sample (decrease in $\mathrm{CN} / \mathrm{TP}=0 \%$ ), 14 out of 25 (52\%) correctly identified the odd sample, which is significant at $P<0.05$ (Lawless and Heymann, 1998). The critical value at level of $P<0.05$ is 13 out of 25 panelists correctly identifying the odd sample. Only five out of 25 panelists correctly identified odd samples in both sets of three samples, which is a further indication that the level of proteolysis in this experiment (i.e., decrease of $4.76 \%$ in $\mathrm{CN} / \mathrm{TP}$ ) is probably near the threshold in skim milk for the most sensitive 50\% of the population of the panelists. In milk containing $2 \%$ fat, there may be a masking effect by the fat. Further work is needed to more clearly define flavor threshold of off-flavors produced by the action of native milk proteases.

\section{CONCLUSIONS}

Based on the conditions of the present study it can be concluded that the geometric mean best estimated detection threshold for off-flavors caused by lipolysis in $2 \%$ fat milk carried out by native milk lipases was in the range of 0.32 to 0.351 meq of FFA/kg of milk, with $34 \%$ of the panelists having detection thresholds at or below 0.250 meq of FFA $/ \mathrm{kg}$ of milk. The threshold detection of off-flavor in skim milk produced by the action of native milk proteases is less than a decrease of CN/ TP of $4.76 \%$, but this value appears to be near the threshold.

\section{ACKNOWLEDGMENTS}

The authors are grateful to the staff at the Cornell Teaching and Research Farm (Ithaca, NY), DairyOne (Ithaca, NY), and Food Science Department Pilot Plant (Ithaca, NY) for their technical assistance. We also would like to thank Tom Burke, Nancy Carey, Maureen Chapman, Bob Kaltaler, Laura Landolf, Joanna Lynch,
Ammar Olabi, and Pat Wood for technical support in chemical and microbial analysis. The authors also thank the Northeast Dairy Food Research Center (Ithaca, NY) and the New York State Milk Promotion Board (Albany, NY) for financial support.

\section{REFERENCES}

Association of Official Analytical Chemists. 2000. Official Methods of Analysis. 17th ed. AOAC, Arlington, VA.

Azzara, C. D., and P. S. Dimick. 1985. Lipolytic enzymes activity of macrophages in bovine mammary gland secretions. J. Dairy Sci. 68:1804-1812.

Castberg, H. G. 1992. Lipase activity. IDF Bull. 271:18-20. Int. Dairy Fed., Brussels, Belgium.

de Rham, O., and A. T. Andrews. 1982. Qualitative and quantitative determination of proteolysis in mastitic milks. J. Dairy Res. 49:587-596.

Harwalkar, V. R., B. Boutin-Muma, H. Cholette, R. C. McKellar, and D. B. Emmons. 1989. Isolation and partial purification of astringent compounds from ultra-high temperature sterilized milk. J. Dairy Res. 56:367-373.

Hotchkiss, J. H., J. H. Chen, and H. T. Lawless. 1999. Combined effects of carbon dioxide addition and barrier films on microbial and sensory changes in pasteurized milk. J. Dairy Sci. 82:690695.

Lawless, H. T., and H. Heymann. 1998. Pages 173-207 in Sensory Evaluation of Food: Principles and Practices. Chapman \& Hall, New York.

Ma, Y., C. Ryan, D. M. Barbano, D. M. Galton, M. Rudan, and K. Boor. 2000. Effects of somatic cell count on quality and shelf-life of pasteurized fluid milk. J. Dairy Sci. 83:264-274.

Ma, Y., D. M. Barbano, and M. V. Santos. 2003. Effect of $\mathrm{CO}_{2}$ addition to raw milk on proteolysis and lipolysis at $4^{\circ} \mathrm{C}$. J. Dairy Sci. 86:1616-1631.

Marshall, R. T., ed. 1993. Standard Methods for the Examination of Dairy Products, 16th ed. Am. Publ. Health Assoc., Inc., Washington, DC.

Meilgaard, M., G. V. Civille, and B. T. Carr. 1991. Sensory Evaluation Techniques, 2nd ed. CRC Press, Inc., Boca Raton, FL.

Olivecrona, T., S. Vilaro, and G. Bengtsson-Olivecrona. 1992. Indigenous enzymes in milk, II. Lipases. Pages 292-305 in Advanced Dairy Chemistry. Vol. 1. P.F. Fox, ed. 2nd ed. Elsevier Applied Science, New York.

Politis, I., E. Lachance, E. Block, and J. D. Turner. 1989. Plasmin and Plasminogen in Bovine milk: A relationship with involution? J. Dairy Sci. 72:900-906. 
Richardson, B. C. 1983. The proteinase of bovine milk and the effect of pasteurization on their activity. N.Z. J. Dairy Sci. Technol. 18: $233-245$.

Saeman, A. I., R. J. Verdi, D. M. Galton, and D. M. Barbano. 1988. Effects of mastitis on proteolytic activity in bovine milk. J. Dairy Sci. 71:505-512.

Shipe, W. F., R. Bassete, D. Deane, W. L. Dunkley, E. G. Hammond, J. W. Harper, D. H. Kleyn, M. E. Morgan, J. H. Nelson, and R. A. Scanlan. 1978. Off-flavors of milk: Nomenclature, standards and bibliography. J. Dairy Sci. 61:857-858.

Shipe, W. F., G. F. Senyk, and K. B. Fountain. 1980. Modified copper soap solvent extraction method for measuring free fatty acids in milk. J. Dairy Sci. 63:193-198.
Smith, E. B., D. M. Barbano, and J. M. Lynch. 1995. Infrared analysis of milk: effect of homogenizer and optical filter selection on apparent homogenization efficiency and repeatability. J. AOAC Int. $1225-1233$.

Verdi, R. J., and D. M. Barbano. 1988. Preliminary investigation of the properties of somatic cell proteases. J. Dairy Sci. 71:534-538.

Verdi, R. J., and D. M. Barbano. 1991. Properties of proteases from milk somatic cells and blood leukocytes. J. Dairy Sci. 74:20772081.

Verdi, R. J., D. M. Barbano, M. E. Dellavalle, and G. F. Senyk. 1987. Variability in true protein, casein, nonprotein nitrogen, and proteolysis in high and low somatic cell milks. J. Dairy Sci. 70:230-242. 